\title{
Association between craniovertebral junction abnormalities and syringomyelia in patients with chiari malformation type-1
}

Amro F. Al-Habib, MD, FRCSC, Hissah Al Abdulsalam, MD, Jehad Abmed, MD, Fahad Albadr, MD, Wajda Alhothali, MD, Abdullah Alzahrani, MD, Abdullah Abojamea, PhD, Abdullah Altowim, MD, Anhar Ullah, MSc, Metab Alkubeyyer, MD.

\begin{abstract}

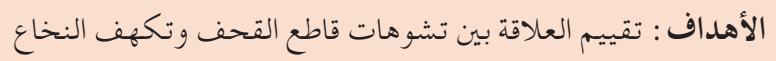

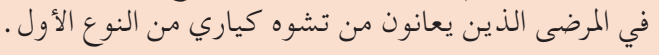

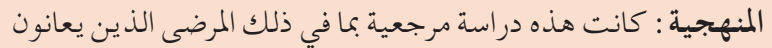

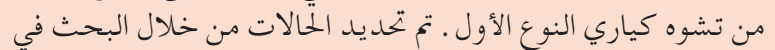

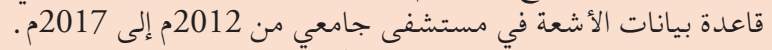

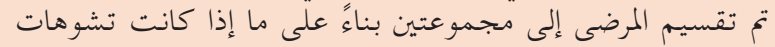

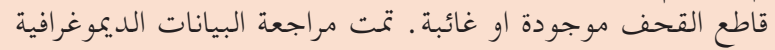

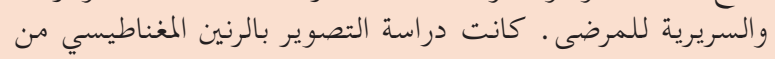

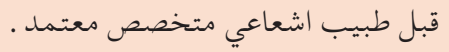

النتائج : تم تضمين أربعة وستين مريضا على التو الي من المرضى الذين الذين

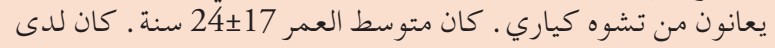

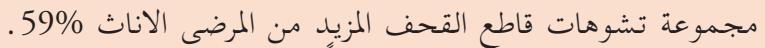

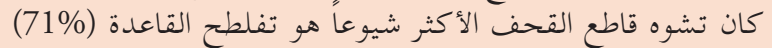

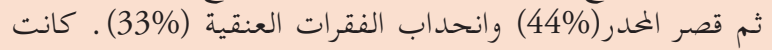

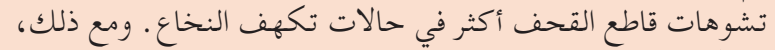

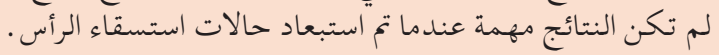
الحنلاصة : بين مرضى كياري النوع الأول تم العثور على تشوهات

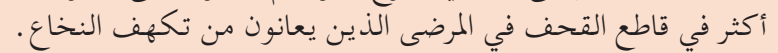

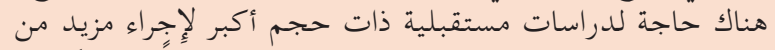

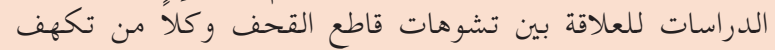

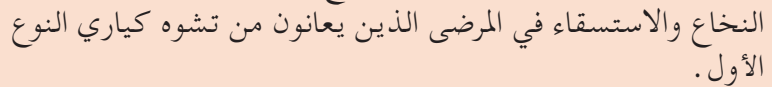

Objectives: To assess the correlation between craniovertebral junction (CVJ) abnormalities and syringomyelia in patients with Chiari malformation type-1 (CM1).

Methods: This was a retrospective study including patients with CM1. Identification of cases was done by searching a radiology database at a university hospital from 2012 to 2017 . Patients were divided into 2 groups based on whether CVJ abnormalities were present $(\mathrm{CVJ}+)$ or absent (CVJ-). The patients' demographic and clinical data were reviewed. All magnetic resonance imaging studies were examined by a certified neuroradiologist.

Results: Sixty-four consecutive patients with CM1 were included. The mean age was $24 \pm 17$ years; $59 \%$ were females. The CVJ+ group had more female patients $(p=0.012)$. The most frequent CVJ abnormality was platybasia (71\%), followed by short clivus (44\%) and cervical kyphosis (33\%). The CVJ abnormalities were more in Syringomyelia cases $(p=0.045)$. However, the results were not significant when hydrocephalus cases were excluded.

Conclusion: Among CM1 patients, CVJ abnormalities were found more in patients with syringomyelia. Future studies with larger sample size are required to further study the correlation between CVJ abnormalities and both syringomyelia and hydrocephalus in CM1 patients.

Neurosciences 2020; Vol. 25 (4): 308-315 doi: 10.17712/nsj.2020.4.20200008

From the Division of Neurosurgery (Al-Habib, Abdulsalam, Ahmed, Alhothali, Alzahrani, Altowim), Department of Surgery, College of Medicine, Department of Radiology (Abojamea, Albadr, Alkubeyyer), Department of Cardiac Sciences (Ullah), King Fahad Cardiac Center, College of Medicine, King Saud University, Riyadh, Kingdom of Saudi Arabia.

Received 19th March 2020. Accepted 21st May 2020.

Address correspondence and reprint request to: Dr. Amro Al-Habib, Division of Neurosurgery, Department of Surgery, College of Medicine, King Saud University, Riyadh, Kingdom of Saudi Arabia. E-mail:amro.alhabib@gmail.com

ORCID ID: https://orcid.org/0000-0001-6960-9170 
C hiari malformation type-1 (CM1) was first described in 1891 by Austrian pathologist Hans Chiari. ${ }^{1,2}$ The CM1 is defined as caudal displacement of the cerebellar tonsils below the foramen magnum by 5 $\mathrm{mm}$ or more. ${ }^{3,4}$ This definition is merely a radiological definition. In the literature, the degree of cerebellar tonsil displacement varies from $3 \mathrm{~mm}$ to $5 \mathrm{~mm} .{ }^{4}$ CM1 affects approximately $1 \%$ of the population and may involve a spectrum of neurologic involvement. ${ }^{2}$ Syringomyelia is reported in $25 \%$ of CM1 cases and may cause irreversible damage to the spinal cord with subsequent neurological deficits. ${ }^{5}$

The pathophysiology of syringomyelia development in patients with CM1 has been extensively studied. ${ }^{6-9}$ Majority of publications indicated a block to the cerebrospinal fluid (CSF) circulation at the level of the craniovertebral junction (CVJ). ${ }^{8} 9$ Subsequently, the cerebrospinal fluid (CSF) accumulates and forms syringomyelia. ${ }^{8,9}$ The source of the CSF forming the syringomyelia can be from the fourth ventricle, the subarachnoid space (SAS), or from an extracellular source. ${ }^{8,9}$ From the 1950 s to the 1970 s, syringomyelia was believed to result from a difference in CSF pressure between the fourth ventricle and the central canal of the spinal canal. ${ }^{7}$ Theories to explain this mechanism include James Gardner's water-hammer theory, Bernard Williams' cranio-spinal pressure dissociation theory, and Ball and Dayan's theory of tonsillar obstruction to the CSF pathway. ${ }^{10-12}$ In the 1990s, Oldfield believed that the mechanism of the development of syringomyelia involved abnormal CSF flow at the level of the foramen magnum. ${ }^{6,7}$ The descent of the cerebellar tonsils with each cardiac cycle produces a pressure wave in the spinal SAS, and thereby compresses the spinal cord from the outside and propagates a syrinx. ${ }^{7,9}$

Several intradural and extradural factors have been implicated in the pathophysiology of CM1. Among the intradural factors identified during surgery for CM1, the presence of an arachnoid membrane obstructing the foramen of Magendie (i.e., an arachnoid veil) was significantly more frequent in patients with an associated syringomyelia. ${ }^{6}$ Other studies have examined whether the degree of tonsillar descent below foramen magnum in the CM1 patients is a contributing factor to

Disclosure. Authors have no conflict of interests. This study was supported by the College of Medicine Research Center, Deanship of Scientific Research, King Saud University, Riyadh, Saudi Arabia. the development of syringomyelia; however, the impact of tonsillar descent is controversial. ${ }^{6,9,13}$ Some studies have reported that the rate of syringomyelia increases as the degree of tonsillar herniation increases. ${ }^{6,9}$ As a possible explanation for syringomyelia development, other studies ${ }^{14,15}$ have addressed crowding of the SAS at the foramen magnum caused by tonsillar decent. In a study by Doruk et $\mathrm{al}^{15}$, the measured cervicomedullary compression ratio, defined as the ratio of the area occupied by the cerebellar tonsils to the area of the foramen magnum, was significantly correlated with the development of syringomyelia. This ratio could reflect the severity of blockage of the SAS at the CVJ and further supports the previously described mechanisms of syringomyelia development. ${ }^{9}$

Extradural abnormalities at the CVJ are associated with CM1. ${ }^{15}$ Such pathologies include a small posterior cranial fossa, platybasia, basilar invagination, and short clivus. $3,6,8,9$ Several studies have examined the presence of CVJ abnormities in CM1 patients with and without syringomyelia. ${ }^{13,16-21}$ However, the presence of associated syringomyelia within the context of CM1 with and without CVJ abnormalities was inadequately highlighted. For instance, in one study, ${ }^{13}$ syringomyelia existed in $64 \%$ of CM1 patients with a short clivus, compared to $36 \%$ of CM1 patients without a short clivus. In order to further understand the relationship between the presence of one or more CVJ abnormalities and syringomyelia in CM1, the current study was conducted. Such knowledge will likely enhance the understanding of CVJ relationship with CM1 and may aid in the management of syringomyelia in such patients.

Methods. Basic study design. This was a retrospective study. We conducted an electronic search for all cases of Chiari malformation (CM) through the Imaging Picture Archiving and Communication System (PACS) database at a university hospital in Riyadh, Saudi Arabia. All consecutive patients diagnosed with CM from 2012 to 2017 were identified. Only CM1 cases, defined as the displacement of the cerebellar tonsil equal or more than $5 \mathrm{~mm}$ below the foramen magnum, were included. ${ }^{3,4}$ We excluded patients who did not meet the criteria for tonsillar decent or patients with underlying infection or tumors affecting the brain or the spinal cord. The study protocol was approved by the institution's review board.

Radiologic parameters and analysis. Magnetic resonance imaging (MRI) studies of all included patients were carefully reviewed by a certified neuroradiologist who was blinded to the clinical data. The included radiological parameters were selected based on previously 
published data describing their relationship to CVJ abnormalities or to CM. The mid-sagittal T1-weighted view MRI was used to assess the CVJ for the following radiological parameters:

The NTB angle of Welcker (Figure 1A): The angle formed by the line extending from the nasion $(\mathrm{N})$ to the tuberculum $(\mathrm{T})$ and the line extending from the tuberculum to the basion (B). Platybasia is marked by an increased NTB angle more than $130^{\circ} .{ }^{22}$

The length of the clivus (Figure 1B): The line from the inferior tip of the dorsum sellae to the basion. A short clivus is defined as a clival length less than 32 $\mathrm{mm}^{22}$

Clivus canal angle (CCA) (23) (Figure 1B): The angle formed between the line extending from the top of the dorsum sellae to the basion and the line extending from the basion to the line marking the posterior surface of the odontoid process (i.e., between the most inferodorsal portions of C2 to the most superodorsal part of the dens). The clivus canal angle reflects craniocervical kyphosis that may be correlated with ventral brainstem compression. Craniocervical kyphosis is defined as a CCA angle less than $150^{\circ} .{ }^{23}$

Basilar invagination (Figure 2). The tip of the dens is projecting more than $3 \mathrm{~mm}$ above the Chamberlain line. ${ }^{23}$

Other radiologic parameters pertaining to the anatomy the posterior fossa were also evaluated, including the length of the supraocciput (i.e., the line from the opisthion to the internal occipital protuberance; Figure 1C), ${ }^{24}$ the length of McRae's line (i.e., the line from the basion to the opisthion; Figure 2), ${ }^{25-27}$
Twining's line (i.e., the line between the inferior part of the dorsum sellae to the internal occipital protuberance; Figure 1C), ${ }^{23}$ and the length of Chamberlain line (i.e., the line between the dorsum of the hard palate and the opisthion; Figure 1C). ${ }^{28}$

Patients were divided into two groups based on the presence $(\mathrm{CVJ}+)$ or absence $(\mathrm{CVJ}-)$ of an abnormal finding in one of the included parameters related to the CVJ. To be included in the CVJ+ group, a patient had to have at least one of the following features: short

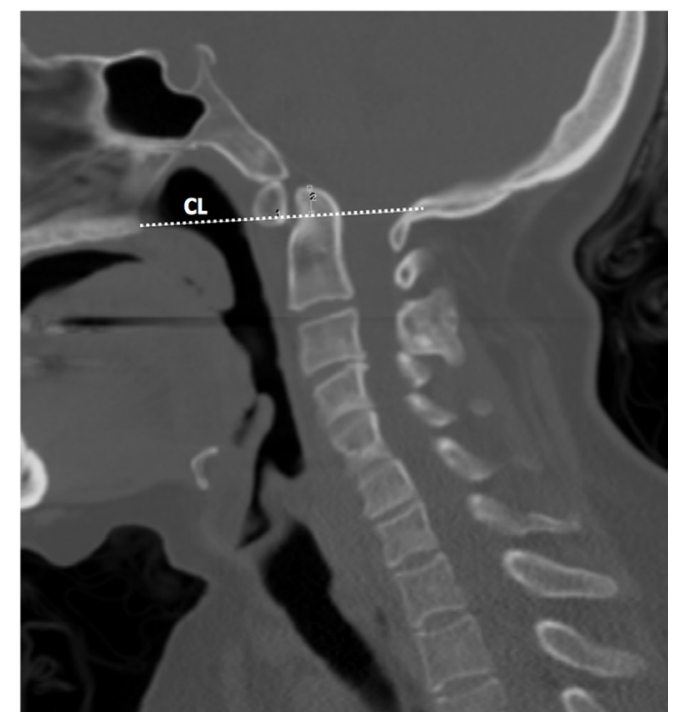

Figure 2- Demonstrating the Chamberlain line used to evaluate basilar invagination. CL - Chamberlain line
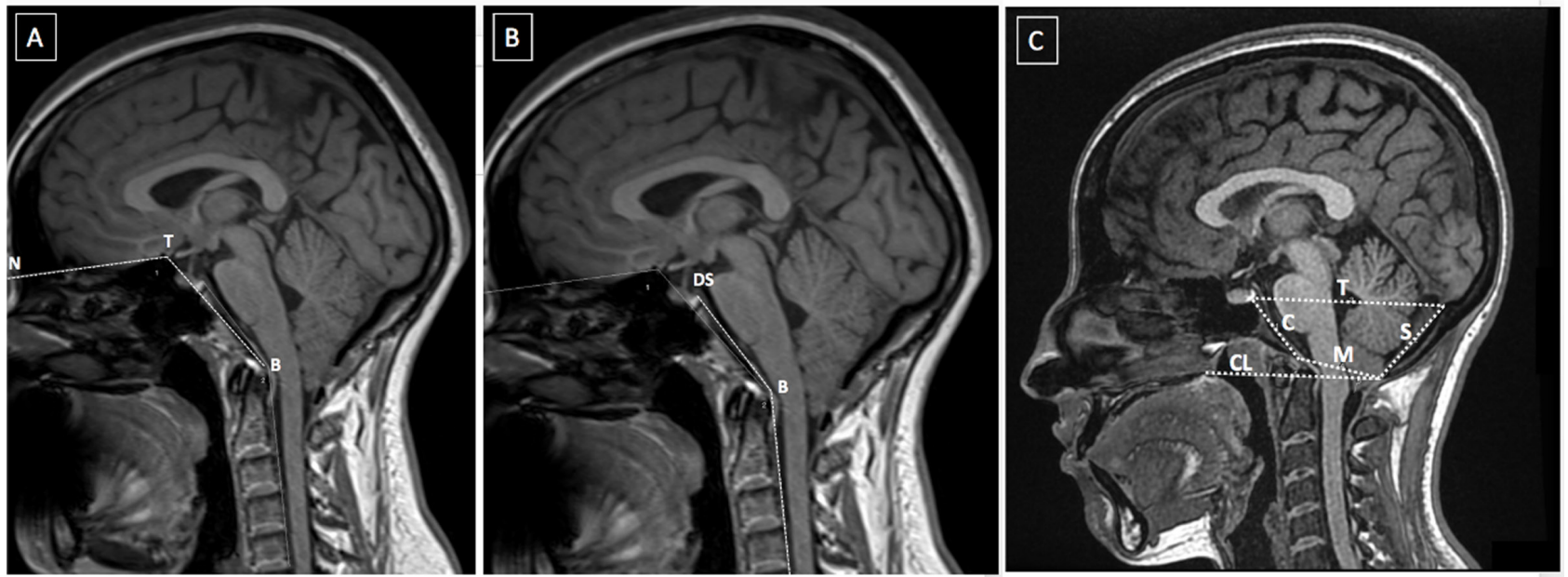

Figure 1- Demonstration of the included anatomical methods to evaluate craniovertebral junction abnormalities. A) points of the NTB angle of Welcker, B) the clivus canal angle, and C) clivus length, supraocciput line (S), McRae's line (M), Twining's line (T), and Chamberlain line (CL). Nasion (N), tuberculum (T), basion (B), and dorsum sellae (DS). 
clivus, craniocervical kyphosis, platybasia, or basilar invagination.

Statistical analysis. Statistical analysis was conducted using Statistical Package for the Social Sciences (SPSS) version 22.0 (SPSS Inc., Chicago, IL, USA). Descriptive data are presented as the mean and the standard deviation for numerical variables. The chi square and Fisher's exact tests were used to compare nominal variables. In addition, a value of $p<0.05$ was considered statistically significant.

Results. Patient demographics and clinical data. We identified 210 patients with CM through the imaging database. We excluded patients with CM type 2 (83 patients), an underlying pathology (59 patients), or tonsillar decent less than $5 \mathrm{~mm}$ (4 patients). Sixty-four

Table 1 - Characteristics of CM-1 patients with and without craniovertebral junction abnormalities.

\begin{tabular}{lcccc}
\hline Patient characteristics & CVJ + & CVJ - & $\begin{array}{c}\text { Total } \\
(\mathbf{n}=64)\end{array}$ & $P$-value \\
\cline { 2 - 4 } & \multicolumn{3}{c}{$\mathbf{n}(\%)$} \\
\hline Age & $25 \pm 17$ & $20 \pm 16$ & $24 \pm 17$ & 0.401 \\
Gender (Female) & $36(67)$ & $2(22)$ & $38(60)$ & 0.012 \\
Clinical Presentations & & & & \\
Symptomatic & $34(79)$ & $8(100)$ & $42(82)$ & 0.154 \\
Asymptomatic & $9(21)$ & $0(0)$ & $9(18)$ & \\
Headache & $13(30)$ & $1(13)$ & $14(27)$ & 0.419 \\
Neck stiffness and pain & $4(9)$ & $0(0)$ & $4(8)$ & 1.000 \\
Dizziness & $2(5)$ & $2(25)$ & $4(8)$ & 0.111 \\
Weakness & $4(10)$ & $0(0)$ & $4(8)$ & 1.000 \\
Paresthesia & $11(26)$ & $0(0)$ & $11(22)$ & 0.176 \\
Gait imbalance & $5(12)$ & $0(0)$ & $5(10)$ & 0.580 \\
Others & $17(40)$ & $2(25)$ & $19(37)$ & 0.694 \\
\hline
\end{tabular}

CVJ+ - With craniovertebral junction abnormalities, CVJ- - Without craniovertebral junction abnormalities patients were ultimately included for evaluation. The average age was $24 \pm 17$ years; 28 pediatrics and 36 adult patients. Most (59\%) patients were females. The characteristics of the 64 patients were summarized in Table 1.

Clinical data for 51 patients were available for analysis. Most (82\%) patients were symptomatic. The most common symptom at presentation was headache (27\%), followed by extremity paresthesia (22\%), and gait imbalance (10\%). Additional clinical symptoms included neck stiffness, dizziness, and weakness.

Craniovertebral junction evaluation and clinical features. Of the 64 patients, the CVJ+ group included 55 patients. Clinical characteristics of the patients were provided in Table 1 . The CVJ-patients were younger than the CVJ+ patients (mean age: 20 years, and 24 years respectively; Table 1); however, this difference was not statistically significant $(p=0.401)$. The CVJ+ group had significantly more female patients than the CVJ-group $(p=0.012$; Table 1). Most patients in the CVJ + and CVJgroups were symptomatic (79\% and $100 \%$, respectively) without any significant statistical difference $(p=0.4862$; Table 1). The most common clinical presentation in the $\mathrm{CVJ}+$ group was headache (30\%). However, patients in the CVJ-group commonly presented with dizziness (25\%) and with other symptoms; such as seizures, sleep apnea, and facial asymmetry (Table 1 ).

Decompressions were performed in 18 (33\%) patients in the CVJ+ group, compared to 1 (11\%) patient within the CVJ- group. This difference was not statistically significant $(p=0.260$; Table 2$)$. Among all included patients in this series, $14(22 \%)$ had hydrocephalus. While there were more patients with hydrocephalus in the CVJ+ group, the difference was not statistically significant ( $p=0.399$; Table 2$)$.

Table 2 - Radiological characteristics of CM-1 patients with and without craniovertebral junction abnormalities.

\begin{tabular}{|c|c|c|c|c|}
\hline \multirow{2}{*}{$\begin{array}{l}\text { Radiological characteristics and } \\
\text { Decompression }\end{array}$} & $\mathrm{CVJ}+$ & $\mathrm{CVJ}-$ & Total $(n=64)$ & \multirow[t]{2}{*}{$P$-value } \\
\hline & \multicolumn{3}{|c|}{ n (\%) } & \\
\hline Syringomyelia $\$$ & $19(37)$ & $0(0)$ & $19(32)$ & 0.045 \\
\hline Hydrocephalus $\$$ & $13(24)$ & $1(11)$ & $14(22)$ & 0.399 \\
\hline Length of supraocciput ${ }^{*}$ & $39.5(6.20)$ & $40.0(12.30)$ & $39.6(6.45)$ & 0.757 \\
\hline Twining's line ${ }^{\wedge}$ & $82.0 \pm 9.1$ & $82.0 \pm 3.1$ & $82.0 \pm 8.5$ & 0.993 \\
\hline Length of McRae's line^ & $34.1 \pm 4.3$ & $35.52 \pm 3.8$ & $34.3 \pm 4.3$ & 0.365 \\
\hline Length of Chamberlain line ${ }^{\wedge}$ & $74.3 \pm 7.5$ & $76.3 \pm 5.9$ & $74.5 \pm 7.2$ & 0.435 \\
\hline Degree of tonsillar displacement ${ }^{\wedge}$ & $11.3 \pm 5.3$ & $12.7 \pm 6.0$ & $11.5 \pm 5.4$ & 0.458 \\
\hline The length of the clivus^ & $32.1 \pm 5.0$ & $38.2 \pm 4.4$ & $33.0 \pm 5.4$ & 0.001 \\
\hline NTB angle ${ }^{\wedge}$ & $134.7 \pm 6.4$ & $125.9 \pm 4.8$ & $133.5 \pm 6.9$ & $<.001$ \\
\hline CC angle ${ }^{\wedge}$ & $152.9 \pm 9.0$ & $158.8 \pm 4.3$ & $153.7 \pm 8.7$ & 0.058 \\
\hline Decompression & $18(33)$ & $1(11)$ & $19(29)$ & 0.260 \\
\hline
\end{tabular}


Table 3 - Characteristics of CM-1 patients with and without syringomyelia.

\begin{tabular}{lcccc}
\hline Patient characteristics & With syringomyelia & Without syringomyelia & Total (n=59) & P-value \\
\cline { 2 - 4 } & \multicolumn{4}{c}{$\mathbf{n}(\%)$} \\
\hline Age & $25 \pm 18$ & $24 \pm 16$ & $24 \pm 17$ & 0.766 \\
Gender (F) & $11(58)$ & $23(59)$ & $34(59)$ & 0.938 \\
Clinical Presentations & $14(93)$ & $27(79)$ & $41(847)$ & 0.224 \\
Symptomatic & $1(7)$ & $7(21)$ & $8(16)$ & \\
Asymptomatic & $6(40)$ & $8(24)$ & $14(29)$ & 0.309 \\
Headache & $3(20)$ & $1(3)$ & $4(8)$ & 0.079 \\
Neck stiffness and pain & $0(0)$ & $4(12)$ & $4(8)$ & 0.298 \\
Dizziness & $4(27)$ & $0(0)$ & $4(8)$ & 0.007 \\
Weakness & $6(40)$ & $5(15)$ & $11(22)$ & 0.069 \\
Paresthesia & $1(7)$ & $4(12)$ & $5(10)$ & 1.000 \\
Gait imbalance & $4(27)$ & $15(44)$ & $19(39)$ & 0.345 \\
Others & \multicolumn{3}{c}{ F - Female } \\
\hline \multicolumn{4}{l}{}
\end{tabular}

Table 4 - Radiological characteristics of CM-1 patients with and without syringomyelia.

\begin{tabular}{|c|c|c|c|c|}
\hline \multirow{2}{*}{$\begin{array}{l}\text { Radiological characteristics and } \\
\text { surgical intervention }\end{array}$} & With syringomyelia & Without syringomyelia & Total $(n=59)$ & \multirow[t]{2}{*}{ P-value } \\
\hline & \multicolumn{3}{|c|}{$\mathrm{n}(\%)$} & \\
\hline Hydrocephalus & $6(32)$ & $7(18)$ & $13(22.03)$ & 0.223 \\
\hline $\mathrm{CVJ}+$ & $19(100)$ & $32(80)$ & $51(86.44)$ & 0.045 \\
\hline CVJ - & $0(0.00)$ & $8(20.00)$ & $8(13.56)$ & \\
\hline length of supraocciput ${ }^{*}$ & $39.1(7.10)$ & $39.8(6.90)$ & $39.6(6.45)$ & \\
\hline Twining's line ${ }^{\wedge}$ & $80.4 \pm 11.8$ & $82.5 \pm 7.1$ & $82.0 \pm 8.5$ & 0.400 \\
\hline Length of McRae's line ${ }^{\wedge}$ & $33.8 \pm 4.3$ & $34.3 \pm 4.3$ & $34.3 \pm 4.3$ & 0.709 \\
\hline length of Chamberlain line ${ }^{\wedge}$ & $75.2 \pm 7.3$ & $74.5 \pm 7.5$ & $74.5 \pm 7.2$ & 0.746 \\
\hline Degree of tonsillar displacement ${ }^{\wedge}$ & $12.8 \pm 5.3$ & $10.9 \pm 5.5$ & $11.5 \pm 5.4$ & 0.210 \\
\hline The length of the clivus & $33.8 \pm 5.4$ & $33.0 \pm 5.0$ & $32.97 \pm 5.35$ & 0.555 \\
\hline NTB angle ${ }^{\wedge}$ & $135.1 \pm 5.2$ & $132.4 \pm 7.3$ & $133.5 \pm 6.93$ & 0.149 \\
\hline CC angle ${ }^{\wedge}$ & $151.9 \pm 10.3$ & $154.2 \pm 8.28$ & $153.7 \pm 8.73$ & 0.356 \\
\hline Decompression & $10(53)$ & $9(23)$ & $19(32)$ & 0.035 \\
\hline VP shunt & $0(0.00)$ & $5(13)$ & $5(8)$ & 0.165 \\
\hline Syrinx shunt & $1(5)$ & $0(0.00)$ & $1(2)$ & 0.322 \\
\hline
\end{tabular}

Description ofCVJradiologicalparameters. The most frequent CVJ abnormality in our series was platybasia, which accounted for $71 \%$ of the $\mathrm{CVJ}+$ group. The second most frequent abnormality was a short clivus in 44\% (24 patients), followed by cervical kyphosis in $33 \%$. Among the CVJ+ group, 21 patients were positive for one CVJ abnormality, whereas 34 patients were positive for more than one CVJ abnormity. Patients in the CVJ- group had greater degree of tonsillar decent (Mean: $12.71 \mathrm{~mm}$ ) than patients within the CVJ+ group (Mean: $11.26 \mathrm{~mm}$ ) (Table 2). However, this difference was not statistically significant $(p=0.458)$.

Analysis of syringomyelia. Among all included patients, syringomyelia was detected in 19 patients out of 59 patients for whom MRI of the spine was available for review. Most (93\%) of patients with syringomyelia were symptomatic (Table 3). The clinical presentation of patients with syringomyelia included occipital headache (40\%), neck stiffness (20\%), weakness (27\%), and paresthesia (40\%). Within the syringomyelia group, the most common CVJ abnormality was platybasia (16 patients), which accounted for $84 \%$, followed cervical kyphosis (53\%) and basilar invagination (26\%).

All patients in the syringomyelia group in our series had CVJ+ abnormalities, compared to $80 \%$ within the non-syringomyelia group ( $p=0.045$; Table 2$)$.

Within the syringomyelia group, $10(53 \%)$ patients 
underwent decompression only and 1 (5\%) patient underwent decompression and syrinx shunt, compared to $9(23 \%)$ patients in the non-syringomyelia group who were decompressed and $5(13 \%)$ patients who required VP shunt insertion (Table 4). Following the exclusion of hydrocephalus cases (14 cases), syringomyelia was found more frequent in $\mathrm{CVJ}+$ group (33\%) compared to $(0 \%)$ in CVJ- group, but this difference was not statistically significant $(p=0.166)$.

Discussion. The current study expanded on the findings of previous reports that evaluated CVJ abnormalities in patients with CM1. Various CVJ structural abnormalities have been previously reported in CM1 patients with one or more than one CVJ abnormality. ${ }^{16,29}$ These abnormalities may include: short clivus, decreased posterior fossa volume, basilar invagination, platybasia, atlas assimilation, and odontoid process retroflexion. ${ }^{13,16,24,29-31}$ Such CVJ abnormalities can be found in CM1 patients with and without syringomyelia; however, their correlation with syringomyelia is unclear. ${ }^{32,33}$ Studying one CVJ abnormality might not be sufficient. For instance, a comparative study ${ }^{34}$ of patients with and without basilar invagination demonstrated that patients with basilar invagination were significantly less likely to have syringomyelia. However, basilar invagination was the only CVJ abnormality included in that study. In comparison, the current study was more inclusive by considering several CVJ abnormalities where syringomyelia was more frequent in $\mathrm{CVJ}+$ group compared to CVJ- group. It is possible that CVJ structural abnormalities compromises CSF flow in the SAS and further contributes to the development of syringomyelia. Understanding such correlation may add to the understanding of CM1 pathophysiology and help early recognition and treatment of syringomyelia to prevent irreversible deficits. ${ }^{7}$

The pathophysiology of the development of syringomyelia in CM1 remains a subject of debate. However, it is generally believed that the pathophysiology of syringomyelia is explained by an interruption in the CSF flow dynamics at the level of the foramen magnum. ${ }^{6,7,9}$ Compression of the SAS at the foramen magnum by the cerebellar tonsils has been assumed.6,9 Increased subarachnoid pressure waves subsequently transmit syrinx fluid distally with each cardiac cycle. Subsequently, syrinx formation and progression results. ${ }^{6,79}$ Intradural arachnoid adhesions may further contribute to syrinx development and progression. ${ }^{29}$ Hence, surgical decompression and duraplasty may reverse the pathophysiological process of syrinx in patients with CM1. ${ }^{7}$ This finding emphasizes the importance of diagnosing syringomyelia early to reverse the pathophysiology of syrinx and prevent irreversible damage.

In other disease conditions, the presence of CVJ bony abnormalities with an associated hindbrain herniation has been postulated to cause CSF flow disturbance with the result of syringomyelia. ${ }^{35-37}$ For instance, this phenomenon was reported in cases of osteogenesis imperfecta in which a progressive reduction in the volume of the posterior fossa secondary to invagination was associated with cerebellar tonsillar abnormalities and syringomyelia. ${ }^{36,37}$ Additionally, mechanical instability at the atlantoaxial joint has been implicated in the pathophysiology of CM1, with surgical fusion been proposed as the appropriate treatment. ${ }^{38,39}$

The pathophysiology of the association between hydrocephalus and CM1 is a subject of debate. ${ }^{40,41} \mathrm{~A}$ raised intracranial pressure caused by hydrocephalus could result in an abnormal tonsillar decent and possibly syringomyelia formation. However, another theory has related the development of hydrocephalus in CM1 patients to the interruption of CSF dynamics in the area of foramen magnum..$^{40,41}$ The disturbed CSF flow was thought to be secondary to the anatomically smaller posterior fossa. ${ }^{40,41}$ While the association is a subject of an ongoing research, it is generally accepted that treating hydrocephalus is a priority in patients presenting with hydrocephalus and CM. ${ }^{40-42}$ In the current study, there was a lack of significant association between abnormalities at the CVJ and syringomyelia following the exclusion of hydrocephalus cases despite more CVJ+ cases in the syringomyelia group. This could be related to the small sample size or to the complex association between hydrocephalus and CM in the presence of abnormalities in the posterior fossa anatomy. This could be further explored in a future study with a larger sample size given such limitation in the present study.

The current study should be interpreted within its existing limitations. The retrospective nature of the study has the possibility of bias. However, bias is less of a concern in the current study because our primary analysis depended on the imaging features of patients with $\mathrm{CM}$ for whom a neuroradiologist reviewed the images and was blinded to the clinical data. While features of abnormal structural changes in the CVJ are countless; we included major abnormalities that have been addressed in the literature with clear normal values.

In conclusion, among CM1 patients, syringomyelia was significantly associated with the presence of CVJ abnormalities. However, when hydrocephalus cases 
were excluded, the association was not significant. Future studies with larger sample size could address the association between CVJ abnormalities and both syringomyelia and hydrocephalus in CM1 patients.

\section{References}

1. Chiari H. Ueber Veränderungen des Kleinhirns infolge von Hydrocephalie des Grosshirns1. DMW-Deutsche Medizinische Wochenschrift 1891; 17: 1172-1175.

2. Loukas M, Noordeh N, Shoja MM, Pugh J, Oakes WJ, Tubbs RS. Hans Chiari (1851-1916). Childs Nerv Syst 2008; 24: 407-409.

3. Elster AD, Chen M. Chiari I malformations: clinical and radiologic reappraisal. Radiology 1992; 183: 347-353.

4. Aboulezz AO, Sartor K, Geyer CA, Gado MH. Position of cerebellar tonsils in the normal population and in patients with Chiari malformation: a quantitative approach with $\mathrm{MR}$ imaging. J Comput Assist Tomogr 1985; 9: 1033-1036.

5. Passias PG, Pyne A, Horn SR, Poorman GW, Janjua MB, Vasquez-Montes D, et al. Developments in the treatment of Chiari type 1 malformations over the past decade. J Spine Surg 2018; 4: 45.

6. Dlouhy BJ, Dawson JD, Menezes AH. Intradural pathology and pathophysiology associated with Chiari I malformation in children and adults with and without syringomyelia. $J$ Neurosurg Pediatr 2017; 20: 526-541.

7. Heiss JD, Patronas N, DeVroom HL, Shawker T, Ennis R, Kammerer W, et al. Elucidating the pathophysiology of syringomyelia. J Neurosurg 1999; 91: 553-562.

8. Koyanagi I, Houkin K. Pathogenesis of syringomyelia associated with Chiari type 1 malformation: review of evidences and proposal of a new hypothesis. Neurosurg Rev 2010; 33: 271-285.

9. Oldfield EH, Muraszko K, Shawker TH, Patronas NJ. Pathophysiology of syringomyelia associated with Chiari I malformation of the cerebellar tonsils: implications for diagnosis and treatment. J Neurosurg 1994; 80: 3-15.

10. Gardner WJ, Angel J. The mechanism of syringomyelia and its surgical correction. Clin Neurosurg 1958; 6: 131-240.

11. Williams B. The distending force in the production of" communicating syringomyelia". Lancet 1969; 2: 189-193.

12. Ball MJ, Dayan AD. Pathogenesis of syringomyelia. Lancet 1972; 2: 799-801.

13. Milhorat TH, Chou MW, Trinidad EM, Kula RW, Mandell M, Wolpert C, et al. Chiari I malformation redefined: clinical and radiographic findings for 364 symptomatic patients. Neurosurgery 1999; 44: 1005-1017.

14. Takeuchi K, Yokoyama T, Ito J, Wada K, Itabashi T, Toh S. Tonsillar herniation and the cervical spine: a morphometric study of 172 patients. J Orthop Sci 2007; 12: 55-60.

15. Doruk E, Ozay R, Sekerci Z, Durmaz HA, Gunes SO, Hanalioglu S, et al. Cervico-medullary compression ratio: A novel radiological parameter correlating with clinical severity in Chiari type 1 malformation. Clin Neurol Neurosurg 2018; 174: 123-128.

16. Vega A, Quintana F, Berciano J. Basichondrocranium anomalies in adult Chiari type I malformation: a morphometric study. $J$ Neurol Sci 1990; 99: 137-145.

17. Schady W, Metcalfe R, Butler P. The incidence of craniocervical bony anomalies in the adult Chiari malformation. J Neurol Sci 1987; 82: 193-203.
18. Sekula RF, Jannetta PJ, Casey KF, Marchan EM, Sekula LK, McCrady CS. Dimensions of the posterior fossa in patients symptomatic for Chiari I malformation but without cerebellar tonsillar descent. Cerebrospinal Fluid Res 2005; 2: 11.

19. Aydin S, Hanimoglu H, Tanriverdi T, Yentur E, Kaynar MY. Chiari type I malformations in adults: a morphometric analysis of the posterior cranial fossa. Surg Neurol 2005; 64: 237-241;

20. Godzik J, Kelly MP, Radmanesh A, Kim D, Holekamp TF, Smyth MD, et al. Relationship of syrinx size and tonsillar descent to spinal deformity in Chiari malformation Type I with associated syringomyelia. J Neurosurg Pediatr 2014; 13 : 368-374.

21. Goel A, Gore S, Shah A, Dharurkar P, Vutha R, Patil A. Atlantoaxial fixation for Chiari 1 formation in pediatric age-group patients: report of treatment in 33 patients. World Neurosurg 2018; 111: e668-e677.

22. Pang D, Thompson DN. Embryology and bony malformations of the craniovertebral junction. Childs Nerv Syst 2011; 27: 523-564.

23. Smoker WR, Khanna G. Imaging the craniocervical junction. Childs Nerv Syst 2008; 24: 1123-1145

24. Alperin N, Loftus JR, Oliu CJ, Bagci AM, Lee SH, Ertl-Wagner $\mathrm{B}$, et al. Magnetic resonance imaging measures of posterior cranial fossa morphology and cerebrospinal fluid physiology in Chiari malformation type I. Neurosurgery 2014; 75: 515-522.

25. Smoker WR. Craniovertebral junction: normal anatomy, craniometry, and congenital anomalies. Radiographics 1994; 14: $255-277$

26. Cronin C, Lohan D, Mhuircheartigh JN, Meehan C, Murphy J, Roche C. CT evaluation of Chamberlain's, McGregor's, and McRae's skull-base lines. Clin Radiol 2009; 64: 64-69.

27. Kwong Y, Rao N, Latief K. Craniometric measurements in the assessment of craniovertebral settling: are they still relevant in the age of cross-sectional imaging? AJR Am J Roentgenol 2011; 196: W421-W5.

28. Bagci A, Lee S, Nagornaya N, Green B, Alperin N. Automated posterior cranial fossa volumetry by MRI: applications to Chiari malformation type I. AJNR Am J Neuroradiol 2013; 34: 1758-1763.

29. Menezes AH. Primary craniovertebral anomalies and the hindbrain herniation syndrome (Chiari I): data base analysis. Pediatr Neurosurg 1995; 23: 260-269.

30. Urbizu A, Poca MA, Vidal X, Rovira A, Sahuquillo J, Macaya A. MRI-based morphometric analysis of posterior cranial fossa in the diagnosis of chiari malformation type I. J Neuroimaging 2014; 24: 250-256.

31. Pindrik J, Johnston JM. Clinical presentation of Chiari I malformation and syringomyelia in children. Neurosurg Clin NAm 2015; 26: 509-514.

32. Banerji NK, Millar JH. Chiari malformation presenting in adult life: its relationship to syringomyelia. Brain 1974; 97 : 157-168.

33. Paul KS, Lye RH, Strang FA, Dutton J. Arnold-Chiari malformation: review of 71 cases. J Neurosurg 1983; 58: 183-187.

34. Klekamp J. Chiari I malformation with and without basilar invagination: a comparative study. Neurosurgical focus 2015; 38: E12.

35. Elisevich K, Fontaine S, Bertrand G. Syringomyelia as a complication of Paget's disease: Case report. J Neurosurg 1987; 66: 611-613. 
36. Kurimoto M, Ohara S, Takaku A. Basilar impression in osteogenesis imperfecta tarda: case report. J Neurosurg 1991; 74: 136-138.

37. Sawin PD, Menezes AH. Basilar invagination in osteogenesis imperfecta and related osteochondrodysplasias: medical and surgical management. J Neurosurg 1997; 86: 950-960.

38. Kimura Y, Seichi A, Gomi A, Kojima M, Inoue H, Kimura A. Acquired Chiari malformation secondary to atlantoaxial vertical subluxation in a patient with rheumatoid arthritis combined with atlanto-occipital assimilation. Neurol Med Chir (Tokyo) 2012; 52: 683-686.

39. Goel A. Is atlantoaxial instability the cause of Chiari malformation? Outcome analysis of 65 patients treated by atlantoaxial fixation. J Neurosurg Spine 2015; 22: 116-127.
40. Massimi L, Pennisi G, Frassanito P, Tamburrini G, Di Rocco C, Caldarelli M. Chiari type I and hydrocephalus. Childs Nerv Syst 2019; 35: 1701-1709.

41. Di Rocco C, Frassanito P, Massimi L, Peraio S. Hydrocephalus and Chiari type I malformation. Childs Nerv Syst 2011; 27: 1653-1664.

42. Hayhurst C, Osman-Farah J, Das K, Mallucci C. Initial management of hydrocephalus associated with Chiari malformation Type I-syringomyelia complex via endoscopic third ventriculostomy: an outcome analysis. J Neurosurg 2008; 108: 1211-1214.

\section{Supplements}

* Supplements will be considered for work including proceedings of conferences or subject matter covering an important topic

* Material can be in the form of original work or abstracts.

* Material in supplements will be for the purpose of teaching rather than research.

* The Guest Editor will ensure that the financial cost of production of the supplement is covered.

* Supplements will be distributed with the regular issue of the journal but further copies can be ordered upon request.

* Material will be made available on Saudi Medical Journal website 